Journal of Applied Pharmaceutical Science Vol. 5 (11), pp. 084-089, November, 2015

Available online at http://www.japsonline.com

DOI: $10.7324 / \mathrm{JAPS} .2015 .501114$

ISSN 2231-3354 (cc) BY-NC-SA

\title{
Essential Oil Secondary Metabolites Variation of Salvia palaestina Leaves Growing wild from Different Locations in Palestine
}

\author{
Hatem Hejaz ${ }^{1}$, Reem Sabbobeh ${ }^{1,2}$, Hashem Al-Jaas ${ }^{3}$, Ali Jahajha ${ }^{3}$, Saleh Abu-Lafi ${ }^{{ }^{*}}$ \\ ${ }^{1}$ Faculty of Pharmacy, Al-Quds University, P. O. Box 20002, Jerusalem, Palestine. \\ ${ }^{2}$ Quality Control Department, General Directorate of Pharmacy, Ministry of Health, Palestine. \\ ${ }^{3}$ Central Public Health Laboratory, Ministry of Health, Ramallah, Palestine.
}

\begin{tabular}{l} 
ARTICLE INFO \\
\hline Article history: \\
Received on: 05/10/2015 \\
Revised on: $20 / 10 / 2015$ \\
Accepted on: 09/11/2015 \\
Available online: $27 / 11 / 2015$ \\
\hline
\end{tabular}

Key words: Essential oil, Secondary metabolites, Salvia palaestina, GC-MS, Herbal medicine.

\begin{abstract}
Herbal medicine is widely practiced in Palestine. Salvia palaestina (Lamiaceae) in particular is heavily used because of its acquired traditional reputation over the years rather than scientific basis. S. palaestina essential oils contain secondary metabolites whose production is influenced by many factors that determine their composition and yield. Wild leaves of $S$. palaestina were collected from eight different locations in Palestine. Air dried leaves were subjected to steam distillation (SD) and the composition of essential oils was determined for the first time by GC-MS in the electron impact mode. Twenty volatile and semi-volatile components were identified. The major components in all samples were eucalyptol and the percentages ranged from $51.9 \%$ to $63.06 \%$. Other components were found but to a lesser extent mainly $\beta$-Thujene, $\beta$-Myrcene, $( \pm)$-Camphor, $\alpha$-Terpineol, and $\beta$ Caryophyllene.
\end{abstract}

\section{INTRODUCTION}

Salvia is the largest genus of Lamiaceae family that comprises nearly a thousand species (Hedege, 1992). The name is derived from Latin word (salvare) which means 'to save or to cure' in reference to its curable medicinal properties (Keller, 1978). Several studies showed that Salvia genus is a valuable source of potent essential oils (Packham, 1997). Specific biological activities such as antimicrobial, antimalarial, antioxidant, antitumor, antidiabetic, anxiolytic, sedative and antiinflammatory activities were reported (Esmaeili et al., 2008; Kelen and Tepe, 2008; Loizzo et al., 2008; Loizzo et al., 2007; Jaber et al., 2013). Salvia palaestina (Meramia in Arabic), is heavily used in almost every Palestinians home in the form of herbal tea by either infusion or decoction. Its reputation plays an integral part of the cultural heritage and the public healthcare practice (Sawalha, 2008). Nonetheless, the usage of this plant is relied on traditional belief rather than scientific consciousness.

\footnotetext{
* Corresponding Author

Saleh Abu-Lafi, Faculty of Pharmacy, Al-Quds University, P. O. Box

20002, Jerusalem, Palestine.Email: sabulafi@science.alquds.edu
}

S. palaestina essential oils secondary metabolites from Palestine has never been analyzed as per our recent intensive literature survey revealed. It was believed that different factors might determine the composition and yield of these essential oils secondary metabolites. These variables include seasonal and maturity variation, geographical origin, genetic variation, growth stages, part of plant utilized, post-harvest drying and storage conditions (Juergens et al., 2003). In the present study, we investigated the secondary metabolites phytochemicals of wild $S$. palaestina leaves by Gas Chromatography Mass Spectrometry (GC-MS) which is a highly efficient and precise tool used for separation and identification of volatile compounds from oil mixtures.

\section{MATERIALS AND METHODS}

\section{Plant materials}

Wild S. palaestina leaves were collected from eight different locations in Palestine between April and May 2013. Leaves were air dried in the absence of light at room temperature for about one week until constant weight is achieved. 


\section{Reagents}

GC grade n-hexane solvent and anhydrous sodium sulfate salt were purchased from Sigma-Aldrich Inc. (USA). Kovats retention index $(\mathrm{KI})$ reagent that consist of alkane standard mixture were between $\mathrm{C}_{10}-\mathrm{C}_{40}$ (even numbered) were purchased from Fluka, Switzerland. All the reference standards used in the research were kindly supplied by the Central Public Health Laboratory, Ministry of Health, Ramallah-Palestine.

\section{Instrumentation}

Essential oils were analyzed using Perkin Elmer, Clarus Gas Chromatography connected to Clarus $600 \mathrm{C}$ mass spectrometer (USA). The GC-MS was operated in the electron impact ionization mode (EI) at $70 \mathrm{eV}$. Perkin Elmer auto-sampler was used with $2 \mathrm{ml}$ vials. The GC is equipped with a fused silica capillary column; DB-5 MS consisted of (5\% diphenyl polysiloxane, 95\% dimethyl polysiloxane) $28 \mathrm{~m} \mathrm{x} 0.25 \mathrm{~mm}$, coating film thickness is $0.25 \mu \mathrm{m}$ (Restck, USA).Scanning electron microscope (SEM) was high resolution scanning electron microscope (HR SEM) Sirion (FEI Company) using Shottky-type field emission source and secondary electron (SE) detector. The images were scanned at voltage of $5 \mathrm{kV}$.

\section{Extraction of the essential oils by steam distillation}

The essential oils of the $S$. palaestina leaves were isolated by steam distillation using Clevenger type apparatus for three hours. The water distillate was extracted twice with $100 \mathrm{ml}$ hexane. The hexane fractions were combined and dried over anhydrous sodium sulfate. Then, $300 \mu \mathrm{L}$ of hexane extract was diluted to $1 \mathrm{~mL}$ with hexane and $1 \mu \mathrm{L}$ of the resulted diluted sample was injected to GC-MS using optimized method. The oil was obtained by evaporation of the hexane by rotary evaporator.

\section{GC-MS chromatographic condition}

The flow rate of the carrier gas was $1 \mathrm{ml} \mathrm{He} / \mathrm{min}$. Injector temperature was set at $235^{\circ} \mathrm{C}$, the source temperature was at $250{ }^{\circ} \mathrm{C}$ and the interface temperature was at $260{ }^{\circ} \mathrm{C}$. Split ratio of 1:20 was adopted during the entire analysis. The column gradient temperature was held at $50{ }^{\circ} \mathrm{C}$ for 2 minutes, then raised from $50{ }^{\circ} \mathrm{C}$ to $180{ }^{\circ} \mathrm{C}$ at a ramp of $5{ }^{\circ} \mathrm{C} / \mathrm{min}$ and from $180^{\circ}$ to 280 ${ }^{\circ} \mathrm{C}$ at a ramp rate of $15{ }^{\circ} \mathrm{C} / \mathrm{min}$ and held there for extra $5 \mathrm{~min}$. Solvent cut time of 4.5 minutes was used to eliminate the solvent gigantic peak. The mass range was from 50 up to $480 \mathrm{Da}$, and of scan interval of 0.2 seconds.

\section{RESULT AND DISCUSSION}

Aromatic plants in general exhibit significant morphological and phytochemical variability. Even among the same genus, Salvia, morphology is expected to be very variable since it has about a thousand species (Hedege, 1992).

Usually the secondary metabolites are preserved in the trichomes of leaves in order to avoid direct contact with the vital leave tissues. Scanning electron microscopy (SEM) of wild $S$. palaestina fresh leaf was performed. It contains intensive, branched, thin, smooth and dark trichomes which intensity in the lower surface higher than that in the upper surface (Figure 1). This is consistent with the fact that all creatures seek to adapt and cope with its environmental conditions. Thus, S. palaestina leaves is curved to avoid harsh environmental conditions to avoid water and essential oil losses. This also can be observed from the smaller width and from the edges which are curved inward as a cover.

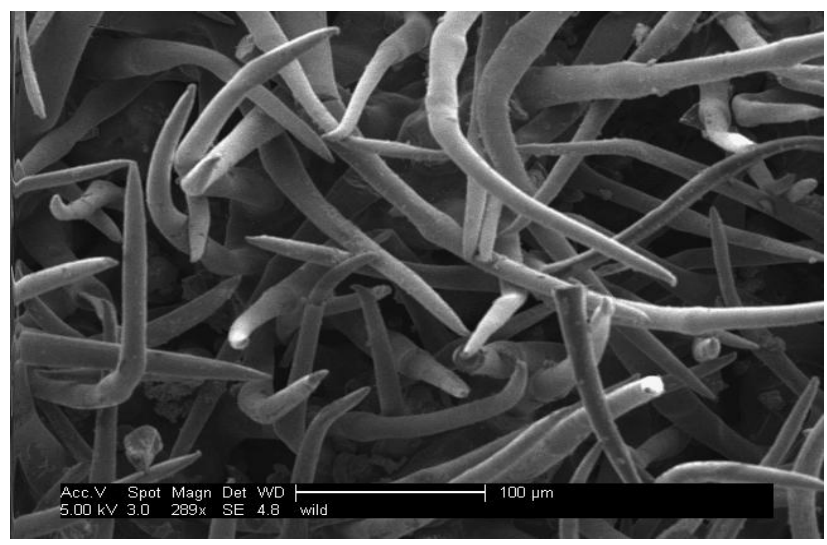

SEM image of wild lower leaf surface

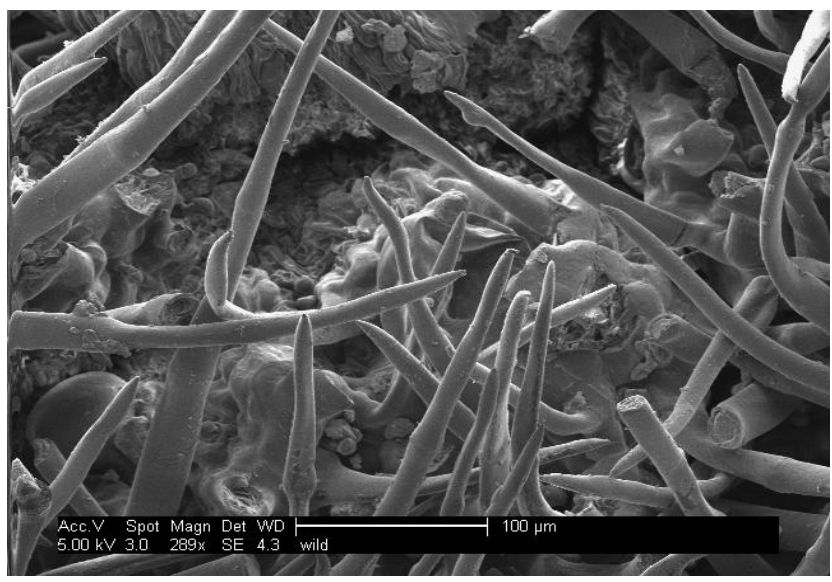

SEM image of wild upper leaf surface

Fig. 1: SEM comparison between lower and upper wild leave of Salvia palaestina

\section{Yield of dry $S$. palaestina leaves oils}

Salvia palaestina leaves were collected from eight different Palestinian governorates between April 2013 and May 2013. Prior the oil extraction, part of fresh leaves was dried and the water loss was calculated to acquire information about water content in the leaves. The essential oils were then isolated by steam distillation (SD). The oil yield was obtained from each location and the ratio between dried and fresh leaves and the water loss $\%$ were determined as summarized in Table 1 and Figure 2.

The average oil yield (w/w) \% was approximately 0.46 $\%$. In some samples however such as in Anabta, it was undetectable, while it was up to $0.72 \%$ in Al-Khader. The water loss of these wild samples was found to range from $36 \%$ (Deir Istiya/Salfit) and 69\% (Al-Khader/Bethlehem) as shown in Table 1 
and Figure 3. The water loss in the wild leaves apparently depends mostly on the topographical nature, rainfall and relative humidity of their location.

Table 1: Salvia palaestina leaves dried/fresh ratio, water loss $\%$ and oil yield

\begin{tabular}{lccc} 
Location & $\begin{array}{c}\text { Dried/Fresh } \\
\text { Weight Ratio }\end{array}$ & $\begin{array}{c}\text { Average } \\
\text { water loss } \\
\text { w/w\% } \\
\text { SD(n=3) }\end{array}$ & $\begin{array}{c}\text { Average oil } \\
\text { yieldw/w\% } \\
\text { SD }(\boldsymbol{n}=\mathbf{3})\end{array}$ \\
\hline Anabta/Tulkarem & $33.2 / 100$ & $66.8 \pm 1.153$ & ND** \\
Beita/Nablus & $33.4 / 100$ & $66.6 \pm 1.168$ & $0.074 \pm 0.17$ \\
Kafr Ni'ma/Ramallah & $49.6 / 100$ & $50.4 \pm 0.985$ & $0.304 \pm 0.096$ \\
Halhul/Hebron & $34.6 / 100$ & $65.4 \pm 0.954$ & $0.698 \pm 0.085$ \\
Al-Khader/Bethlehem & $30.7 / 100$ & $69.3 \pm 1.079$ & $0.72 \pm 0.131$ \\
Ya'bad/Jenin & $46.6 / 100$ & $53.4 \pm 0.874$ & $0.552 \pm 0.095$ \\
Deir Istiya/Salfit & $63.5 / 100$ & $36.5 \pm 0.493$ & $0.434 \pm 0.081$ \\
Abud/Ramallah & $45.3 / 100$ & $54.7 \pm 0.862$ & $0.234 \pm 0.076$ \\
\hline * The oil yield was calculated based on weight of oil to weight of each dried \\
sample. ** ND: Not determined
\end{tabular}

\section{S. palaestina oil yield}



Fig. 2: Oil yield of wild Salvia palaestina leaves

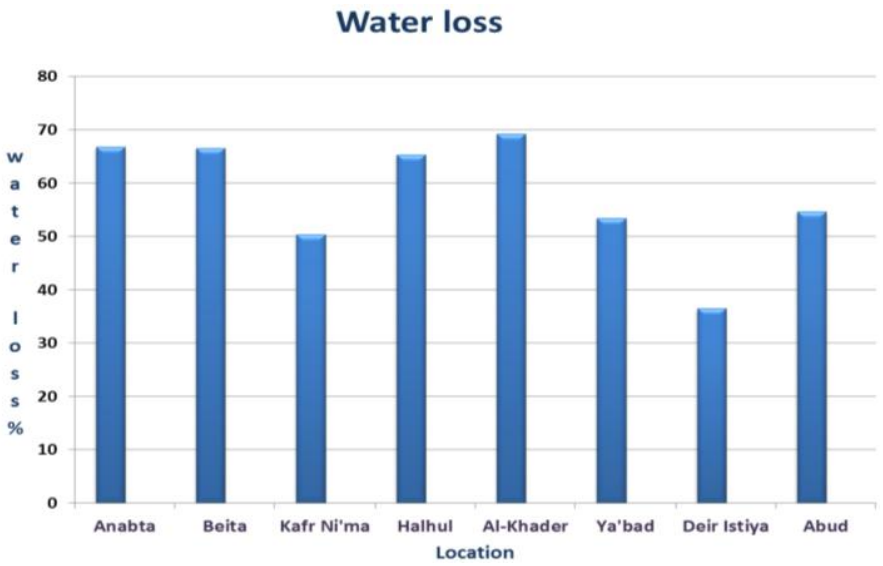

Fig. 3:Water loss of wild Salvia palaestina leaves

\section{Identification of separated components by GC-MS}

The essential oils were analyzed by GC-MS in the Electron Impact (EI) mode and identified by comparing with NIST library database and by calculating Kovats Index (KI) values. The total ion chromatograms (TIC) of the GC-MS that comprise the components in wild oil samples collected from Halhul is shown in Figure 4. Twenty major components were identified. The molecular formula, retention time and KI values are summarized in Table 2. The main essential oils contain monoterpenoids, oxygenated monoterpenoids and to a lesser extent sesquiterpens and diterpens.

Among all, eucalyptol (oxygenated monoterpenoid) was the predominant component in average concentration exceeding $50 \%$. All the essential oils were analyzed by GC-MS in triplicate. The relative standard deviation percentages (RSD \%) were calculated for the essential oil peak areas as shown in Table 3. The precision values were within the acceptable limits.

The GC-MS results were interpreted mainly based on their MS in comparison to typical stored NIST database. The molecular ions and the fragmentation patterns were found to have full match with the NIST library, which indicates excellent conformity of the identified structures.

Table 2: GC-MS components of the secondary metabolites of S. palaestina leaves

\begin{tabular}{|c|c|c|c|c|}
\hline $\begin{array}{l}\text { S. } \\
\text { No. }\end{array}$ & Component & M Formula & RT (mins) & KI \\
\hline 1 & $\alpha$-Thujene & $\mathrm{C}_{10} \mathrm{H}_{16}$ & 6.209 & \\
\hline 2 & Camphene & $\mathrm{C}_{10} \mathrm{H}_{16}$ & 6.635 & \\
\hline 3 & $\beta$-Thujene & $\mathrm{C}_{10} \mathrm{H}_{16}$ & 7.392 & \\
\hline 4 & $\beta$-Myrcene & $\mathrm{C}_{10} \mathrm{H}_{16}$ & 7.736 & \\
\hline 5 & Eucalyptol & $\mathrm{C}_{10} \mathrm{H}_{18} \mathrm{O}$ & 8.95 & 1042 \\
\hline 6 & $\gamma$-Terpinene & $\mathrm{C}_{10} \mathrm{H}_{16}$ & 9.707 & 1072 \\
\hline 7 & trans-4-Thujanol & $\mathrm{C}_{10} \mathrm{H}_{18} \mathrm{O}$ & 10.04 & 1084 \\
\hline 8 & 3-Thujanone & $\mathrm{C}_{10} \mathrm{H}_{16} \mathrm{O}$ & 11.08 & 1120 \\
\hline 9 & $\alpha$-Thujone & $\mathrm{C}_{10} \mathrm{H}_{16} \mathrm{O}$ & 11.41 & 1131 \\
\hline 10 & $( \pm)$-Camphor & $\mathrm{C}_{10} \mathrm{H}_{16} \mathrm{O}$ & 12.25 & 1156 \\
\hline 11 & 3-Pinanone & $\mathrm{C}_{10} \mathrm{H}_{16} \mathrm{O}$ & 12.64 & 1168 \\
\hline 12 & Ocimenol & $\mathrm{C}_{10} \mathrm{H}_{18} \mathrm{O}$ & 12.94 & 1176 \\
\hline 13 & L-Terpinen-4-ol & $\mathrm{C}_{10} \mathrm{H}_{18} \mathrm{O}$ & 13.24 & 1184 \\
\hline 14 & $\alpha$-Terpineol & $\mathrm{C}_{10} \mathrm{H}_{18} \mathrm{O}$ & 13.67 & 1196 \\
\hline 15 & L-Bornyl acetate & $\mathrm{C}_{12} \mathrm{H}_{20} \mathrm{O}_{2}$ & 16.13 & 1293 \\
\hline 16 & Terpinyl acetate & $\mathrm{C}_{12} \mathrm{H}_{20} \mathrm{O}_{2}$ & 17.84 & 1353 \\
\hline 17 & $\beta$-Caryophyllene & $\mathrm{C}_{15} \mathrm{H}_{24}$ & 19.71 & 1419 \\
\hline 18 & $\alpha$-Caryophyllene & $\mathrm{C}_{15} \mathrm{H}_{24}$ & 20.6 & 1458 \\
\hline 19 & Epiglobulol & $\mathrm{C}_{15} \mathrm{H}_{26} \mathrm{O}$ & 23.92 & 1591 \\
\hline 20 & 13-Epi-manool & $\mathrm{C}_{20} \mathrm{H}_{34} \mathrm{O}$ & 31.49 & 2066 \\
\hline
\end{tabular}

Wild $S$. palaestina constituents and percentages from different locations

Palestine is unique not only in its geographical location but also in its topographical features which lead to weather and climate changes which in turns leads to biodiversity (Mendelsohn and Yom-Tov, 1999). Since the composition of essential oil is affected by these factors, the differences in oil composition of $S$. palaestina from one location to another was obvious.

Wild S. palaestina secondary metabolites constituents and percentages were compared from all locations as in Figure 5. Some of the samples contain the twenty components such as in Ya'bad sample.

However, it was obvious that there were certain indigenous volatiles, which distinguished each location. For example, Al-Khader sample was found to be characterized by high levels of eucalyptol, while Beita sample is differentiated with $\beta$ myrcene phytochemical. Abud sample however is characterized with high levels of camphene and camphor while Anabta sampleis distinguished with the sesquiterpene, caryophyllene. 


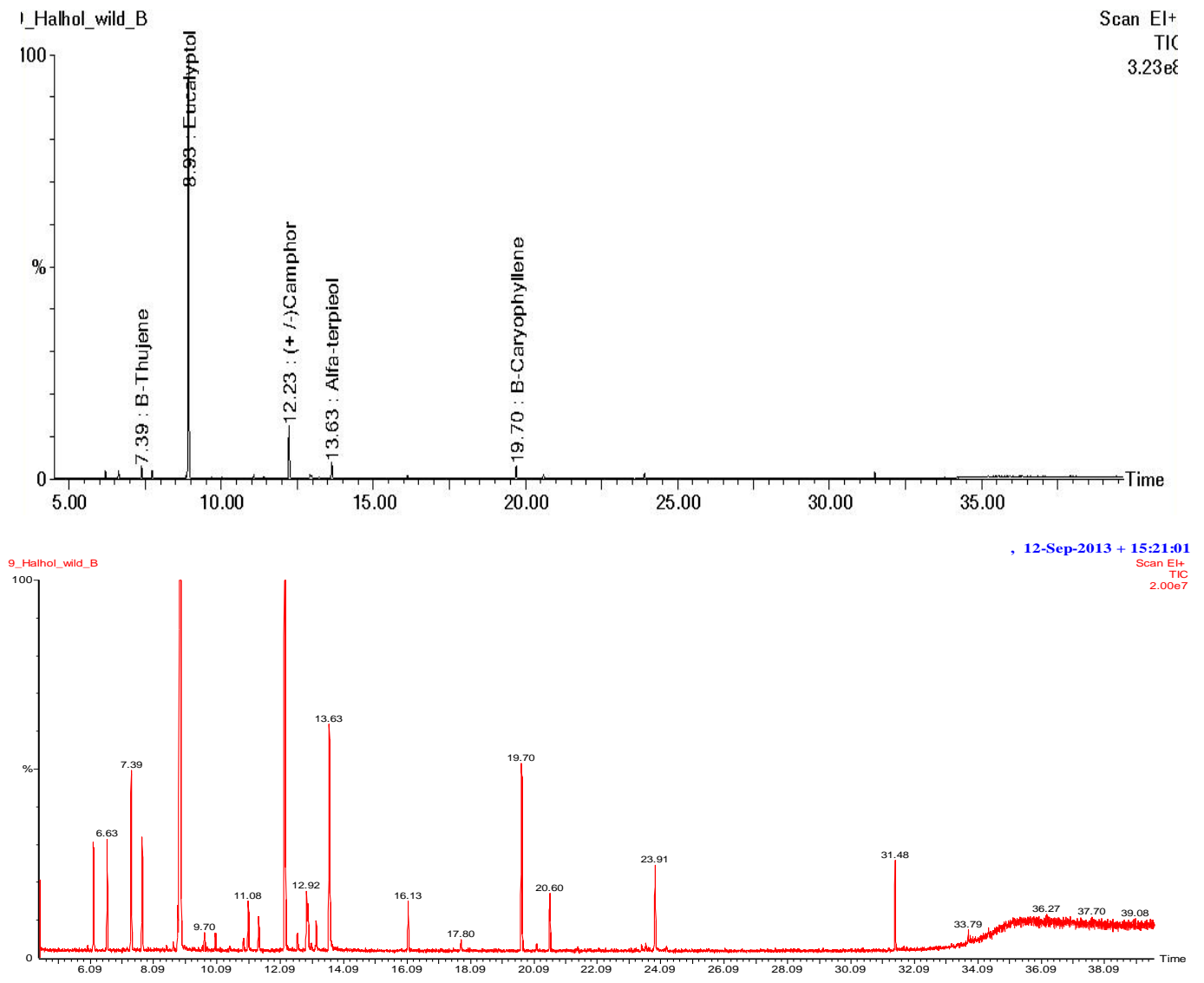

Fig. 4: The TIC GC-MS of unzoomed (A) and zoomed (B) S. palaestina sample collected from Halhul.

The predominant components in all the investigated samples were eucalyptol (more than 50\%), camphor (up to $8.7 \%$ ), caryophyllene, terpineol, $\beta$-thujene and $\beta$-myrcene. These six components represented about $70 \%$ of all components. Eucalyptol is mainly used as an active ingredient in mouthwash, lozenges, ointments inhalants, body powder and cough suppressant preparations. It controls airway mucus hyper-secretion and asthma via inhibition of cytokine production in human monocytes (Juergens et al., 2003; Juergens et al., 2004). In addition, it stimulates immune system response by enhancing the phagocytic ability of human monocytes (Juergens et al., 1998). Eucalyptol has noticeable antimicrobial activity with minimal side effects when applied either topically or systemically. Therefore, it is used in many antiseptic preparations and to used reduce inflammation and pain. Due to its pleasant smell, it is used as a fragrance to impart a fresh and clean aroma in soaps, lotions, detergents and cosmetics. Recently, several studies revealed that it might have anti-tumour activity since it kills leukaemia cells in vitro (Moteki, et al., 2002). Thus, it is advisable to use wild $S$. palaestina leaves in the preparation of pharmaceutical dosage forms that contain eucalyptol as active or inactive ingredient. In order to qualitatively understand the accumulated results, one must keep in mind that secondary metabolites biosynthesis and accumulation in plants is strongly influenced by various biotic and abiotic factors (Smetanska, 2008). Plants are exposed to various degrees of stress, which might be either natural or human-induced factors.
Drought, salinization, water, light, radiation, humidity, atmosphere, pressure, sound waves, soil type and the presence of heavy metals in the soil all might cause substantial effect on yield, type and quality of bioactive components in the oil (Mohammadkhani and Heidari, 2008).

Table 3:The RSD \% of the peaks areas $(n=3)$.

\begin{tabular}{llll}
\hline Component & Average & SD & RSD\% \\
\hline$\alpha$-Thujene & 165855.267 & 5047.194 & 3.043 \\
Camphene & 187710.767 & 537.809 & 0.287 \\
$\beta$-Thujene & 329359.633 & 7693.010 & 2.336 \\
$\beta$-Myrcene & 190186.633 & 3064.475 & 1.611 \\
Eucalyptol & 8738522.000 & 106604.178 & 1.220 \\
$\gamma$-Terpinen & 37752.850 & 4991.750 & 13.222 \\
trans-4-Thujanol & 44436.000 & 3011.080 & 6.776 \\
3-Thujanone & 197462.200 & 3999.825 & 2.026 \\
$\alpha$-Thujone & 160175.300 & 1706.739 & 1.066 \\
Camphor(+-) & 1620297.833 & 46206.939 & 2.852 \\
3-Pinanone & 48232.667 & 2260.049 & 4.686 \\
Ocimenol & 93942.033 & 2419.193 & 2.575 \\
L-Terpinen-4-ol & 55142.833 & 3098.467 & 5.619 \\
$\alpha$-Terpineol & 400727.967 & 12945.368 & 3.230 \\
L-Bornyl acetate & 75580.567 & 2638.140 & 3.491 \\
Terpinyl acetate & 90134.833 & 5014.638 & 5.563 \\
$\beta$-Caryophyllene & 533968.500 & 5816.767 & 1.089 \\
$\alpha$-Caryophyllene & 101798.967 & 4079.204 & 4.007 \\
Epiglobulol & 232372.767 & 13136.220 & 5.653 \\
13-Epimanool & 125295.467 & 10905.166 & 8.704 \\
\hline
\end{tabular}

Due to the aforementioned factors, differences between $S$. palaestina components from one location to another are reasonable. 


\section{Wild S. palaestina from all locations}

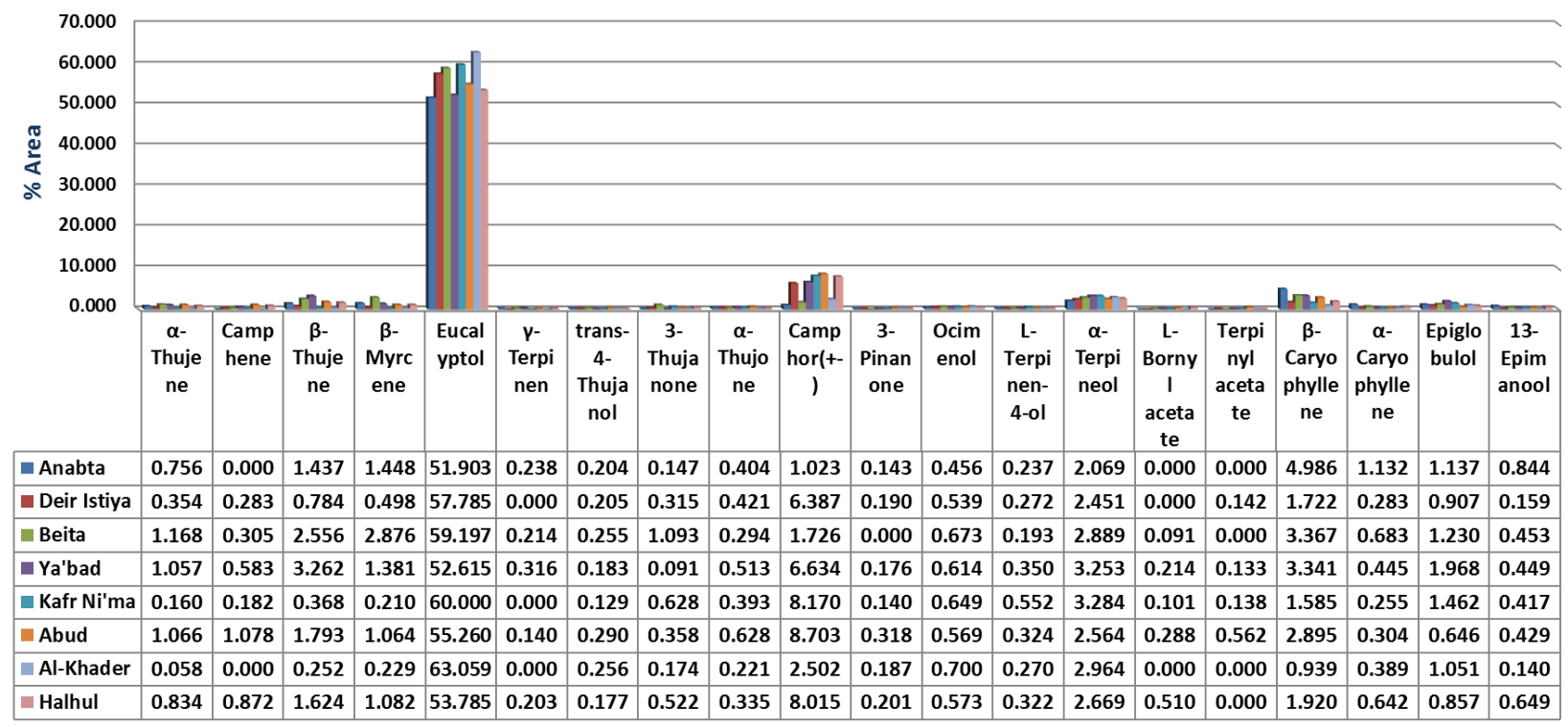

Fig. 5: Wild $S$. palaestina secondary metabolites percentages from all locations

\section{CONCLUSION}

Twenty volatile and semi-volatile components were detected in wild salvia leaves from different locations in Palestine for the first time and eucalyptol was found to be the predominate component in a percentage exceeding 50\%. Other minor components were also found but to a lesser extent namely $\beta$ Thujene, $\beta$-Myrcene, $( \pm)$-Camphor, $\alpha$-Terpineol, and $\beta$ Caryophyllene. Eucalyptolis probablythe principle phytochemical responsible for the pharmacological activities of wild S. palaestina.

\section{ACKNOWLEDGEMENT}

We would like to thank the Central Public Health Laboratory CPHL staff, Ministry of Health in Ramallah for providing the GC-MS instrument for the analysis. Special thanks to Dr. Asad Ramlawi, Director General of Primary Health Care, Ministry of Health for his encouragement. Thanks are extended to Mr. Ibrahim Salem for facilitating this research at the Ministry of Health in Ramallah.

\section{REFERENCES}

Esmaeili A., Rustaiyan A., Nadimi M., Larijani K., Nadjafi F., Tabrizi L., Chalabian F., Amiri H. Chemical composition and antibacterial activity of essential oils from leaves, stems and flowers of Salvia reuterana Boiss. grown in Iran. Nat Prod Res, 2008; 15; 22(6), 516-520.

Hedege I. C. 1992. A global survey of the biogeography of the Labiatae. In: Advances in Labiate science. (Harley R. M., Reynolds, T., eds) Royal Botanic Hardens Kew. 7-18.

JaberS., Abu-Lafi S., Asharif A., Qutob M., Aburemeleh Q. Akkawi M. Potential Antimalarial Activity from Alcoholic Extracts of Wild Salvia palaestina Leaves. British Journal of Pharmacology and Toxicology, 2013; 4(5), 201-206
Juergens U. R., Stober M.,Vetter H. Inhibition of cytokine production and arachidonic acid metabolism by eucalyptol (1.8-cineole) in human blood monocytes in vitro. Eur J Med Res, 1998; $3(11), 508-510$.

Juergens, U. R., Dethlefsen, U., Steinkamp, G., Gillissen, A., Repges, R., \& Vetter, H. Anti-inflammatory activity of 1.8-cineol (eucalyptol) in bronchial asthma: a double-blind placebo-controlled trial. Respir Med, 2003; 97(3), 250-256.

Juergens, U. R., Engelen, T., Racke, K., Stober, M., Gillissen, A., \& Vetter, H. Inhibitory activity of 1,8-cineol (eucalyptol) on cytokine production in cultured human lymphocytes and monocytes. Pulm Pharmacol Ther, 2004; 17(5), 281-287.

Keller M. S. 1978. Mysterious herbs \& roots: ancient secrets for beautie, health, magick, prevention and youth, 1600 B.C.-1900 A.D. Culver City, Calif.: Peace Press.

Kelen M., Tepe B. Chemical composition, antioxidant and antimicrobial properties of the essential oils of three Salvia species from Turkish flora. Bioresour Technol, 2008; 99(10), 4096-4104.

Loizzo M. R., Tundis R., Menichini F., Saab A. M., Statti G. A., Menichini F. Cytotoxic activity of essential oils from labiatae and lauraceae families against in vitro human tumor models. Anticancer Res., 2007; 27(5A), 3293-3299.

Loizzo M. R., Saab A. M., Tundis R., Menichini F., Bonesi M., Piccolo V., Statti G.A., de Cindio B., Houghton P.J., Menichini F. In vitro inhibitory activities of plants used in Lebanon traditional medicine against angiotensin converting enzyme (ACE) and digestive enzymes related to diabetes. J Ethnopharmacol., 2008; 119(1), 109-116.

Mendelsohn H., Yom-Tov Y. 1999. Fauna Palaestina: Mammalia of Israel. Jerusalem. The Israel Academy of Sciences and Humanities, Ketrepress Enterprise, Jerusalem.

Mohammadkhani N., Heidari R. Water stress induced by polyethylene glycol 6000 and sodium chloride in two maize cultivars. Pak J Biol Sci., 2008; 11(1), 92-97.

Moteki H., Hibasami H., Yamada Y., Katsuzaki H., Imai K., KomiyaT. Specific induction of apoptosis by 1,8-cineole in two human leukemia cell lines, but not a in human stomach cancer cell line. Oncol Rep, 2002; 9(4), 757-760.

Packham C. L. Re: Essential oils and 'aromatherapy': their role in healing. J R Soc Health, 1997; 117(6), 400. 
Perry N. B., Anderson R. E., Brennan N. J., Douglas M. H., Heaney A. J., McGimpsey J. A., Smallfield B. M. Essential oils from dalmatian Sage (Salvia officinalis 1.): variations among individuals, plant parts, seasons, and sites. J Agric Food Chem, 1999; 47(5), 2048-2054.

Sawalha A. F., Sweileh W. M., Zyoud S. H., Jabi S. W. Selftherapy practices among university students in Palestine: focus on herbal remedies. Complement Ther Med, 2008; 16(6), 343-349.

Smetanska, I. Production of secondary metabolites using plant cell cultures. Adv Biochem Eng Biotechnol, 2008; 111, 187-228.

\section{How to cite this article:}

Hatem Hejaz, Reem Sabbobeh, Hashem Al-Jaas, Ali Jahajha, Saleh Abu-Lafi. Essential Oil Secondary Metabolites Variation of Salvia palaestina Leaves Growing wild from Different Locations in Palestine. J App Pharm Sci, 2015; 5 (11): 084-089. 